\title{
Determiner agreement and noun conjunction ${ }^{1}$
}

\author{
TRACY HOLLOWAY KING \\ Palo Alto Research Center \\ MARY DALR YMPLE \\ King's College London
}

(Received 4 October 2002; revised I4 May 2003)

\begin{abstract}
Determiner-noun agreement in English and many other languages appears to be straightforwardly describable; singular determiners go with singular nouns, and plural determiners go with plural nouns. The situation is more complicated with coordinated nouns, however, since unexpected agreement patterns often result. Our theory makes the correct predictions for English and other languages by combining two crucial insights: the dual nature of agreement features inside the noun phrase (Kathol I999; Sadler 1999, 2003; Wechsler \& Zlatić 2000, 2003) and the distinction between distributive and nondistributive features in coordination (Dalrymple \& Kaplan 2000).
\end{abstract}

\section{Determiners AND COORDinAtED NOUNS IN ENGLish}

In many languages, including English, determiners show number agreement with the head noun of a phrase, as in example (I); singular determiners go with singular nouns, and plural determiners go with plural nouns.

(I) (a) a boy/this boy/*these boy

(b) these boys/*a boys $/ *$ this boys

Surprisingly, these same constraints hold even with coordinated head nouns. The examples in (2) show that coordinated singular nouns like boy and girl require a singular determiner, not a plural one.

(2) (a) this boy and girl/a boy and girl

(b) *these boy and girl

[I] Our interest in this topic began with a discussion on the Linguist List in 1994 under the heading '*These man and woman', initiated by Alexis Manaster-Ramer. We're grateful to those who have discussed these issues with us over the years: Albert Badalian, Rens Bod, Cleo Condoravdi, Mark Donohue, Helge Dyvik, Yehuda Falk, Danièle Godard, Irene Hayrapetian, Ron Kaplan, Lauri Karttunen, Will Leben, Jean-Philippe Marcotte, Stella Markantonatou, Lutz Marten, Manana Mgeladze, Tara Mohanan, Paul Newman, MaríaEugenia Niño, Almerindo Ojeda, Valeria de Paiva, Mike Polyakov, Stefan Riezler, Hinrich Schütze, Hadar Shemtov, Julie Solomon, Paolo Chagas de Souza, Alex Vasserman, Steve Wechsler, Annie Zaenen, Sasha Jacob Zamler, the audience of the LFG-2002 conference, Athens, and two anonymous $J L$ referees. We would particularly like to thank Lutz Marten and Paul Newman, who provided data crucial in formulating the analysis we present in this paper. 
This requirement seems to conflict with properties of the phrase as a whole: as shown in (3), this boy and girl behaves like a plural phrase, not a singular one, for purposes of verb agreement and control of anaphora (examples (3c) and (3d) are naturally-occurring examples from the Internet).

(3) (a) This boy and girl are/*is eating a pizza.

(b) This boy and girl saw themselves/*himself/*herself in the mirror.

(c) This boy and girl have become skilled at setting the places for their classmates at snacktime. (http://www.edvid.com/infant.asp)

(d) In this type of 'marriage' ... a man and woman who have lived together for a certain period of time and who hold themselves to be husband and wife are considered to be married even without a license and a formal ceremony.

(http://www.itslegal.com/infonet/family/common.html)

Similarly, a plural determiner with coordinated nouns requires each noun to be plural, as shown in (4). Mixed coordinations in which one noun is singular and one is plural are unacceptable, $(4 b)$, and instead separate determiners are required, (4c).

(4) (a) these boys and girls

(b) *these boys and girl

(c) these boys and this girl

Example (5) shows that English determiner-noun agreement is not a case of closest-conjunct agreement for determiners.

(5) (a) *these [boys and girl]

(b) *this [boy and girls]

In closest-conjunct agreement, the agreeing element agrees with whichever conjunct is closest to it. In particular, closest-conjunct agreement permits coordinations containing both singular and plural nouns, as long as the determiner agrees with the closest conjunct. If English determiners obeyed closestconjunct agreement, the examples in (5) would be grammatical, since these agrees in number with the closest conjunct, boys, in (5a), and this agrees with boy in $(5$ b). Sadler $(1999,2003)$ provides a very interesting analysis of closestconjunct agreement, though with slightly different assumptions about the status and geometry of different sets of agreement features from the ones we make here. We will not provide an account of closest-conjunct agreement here, though we hope to provide an integrated account in future work.

\section{ANALYSIS}

In recent work, Wechsler \& Zlatić (2000) propose that there are two types of agreement features associated with nouns, CONCORD features and INDEX features. CONCORD features, closely related to the declension class of a noun, generally control agreement between a noun and its determiners and 
adjectives. In contrast, INDEX features, closely related to the noun's semantics, control agreement between a noun phrase and a bound pronoun and often control verb agreement. We also adopt a two-way distinction in agreement features, positing CONCORD and INDEX agreement features at the level of functional structure. ${ }^{2}$ Wechsler \& Zlatić's distinction between CONCORD and INDEX features follows work in HPSG by Pollard \& Sag (1994), Kathol (I999), and others, which also makes a two-way distinction in agreement features.

Our account predicts that coordinated singular nouns like boy and girl behave as if they had a singular CONCORD value but a plural INDEX value, which explains why coordinated singular nouns require a singular determiner but plural verb agreement. We will show that the CONCORD value of a coordinate phrase is determined by the CONCORD values of each conjunct: for example, a coordinate phrase has singular CONCORD only if each conjunct has singular CONCORD. In contrast, the INDEX value of a coordinate phrase depends on the properties of a phrase as a whole: a coordinate phrase has singular INDEX if it refers to a single individual, and plural INDEX if it refers to more than one individual.

The analysis is presented within the theory of Lexical Functional Grammar (LFG); for an overview and introduction to the theory, see Bresnan (200I), Dalrymple (200I), Falk (200I). The simplified phrase structure rule in (6) is the one generally assumed for noun phrases in LFG (Dalrymple 200I). According to this rule, a noun phrase may consist of an optional determiner and a following noun. LFG phrase structure rules are also annotated with information about functional structure (f-structure), the level at which grammatical relations like subject and object are represented. The up arrow $\uparrow$ refers to the f-structure corresponding to the mother node in the rule, and the down arrow $\downarrow$ refers to the f-structure of the daughter node. In the rule in (6), the $\uparrow=\downarrow$ functional annotations on the daughter nodes in the rule require the f-structures for the daughter nodes to be the same as the f-structure for the mother node.

$$
\mathrm{NP} \rightarrow\left(\begin{array}{c}
\text { Det } \\
\uparrow=\downarrow
\end{array}\right) \underset{\uparrow=\downarrow}{\mathrm{N}}
$$

The lexical entries we propose for the demonstrative determiner this and the noun boy are given in (7) (here and throughout the paper, only relevant details are shown).

[2] Corbett (200I) provides an instructive discussion of agreement terms, pointing out that some authors use the terms 'agreement' and 'concord' synonymously (Moravcsik 1978), some treat agreement as a subtype of concord (Greenberg 1978), and some treat concord as a subtype of agreement (Bloomfield I933). Our usage, and Wechsler \& Zlatić's, follows Bloomfield's most closely: we treat the distinction as corresponding in broad terms to agreement inside the noun phrase (CONCORD agreement) vs. agreement outside the noun phrase (INDEX agreement). The correspondence turns out not to be exact, however; we will see that there are cases in which agreement between a determiner and a noun depends on INDEX and not CONCORD features. 
(7) this $(\uparrow \mathrm{SPEC})=$ 'THIS'

$$
\begin{array}{ll} 
& (\uparrow \text { CONCORD NUM })=\mathrm{SG} \\
\text { boy } & (\uparrow \text { PRED })={ }^{\circ} \mathrm{BOY}, \\
& (\uparrow \text { CONCORD NUM })=\mathrm{SG} \\
& (\uparrow \text { INDEX NUM })=\mathrm{SG}
\end{array}
$$

The determiner this requires its f-structure to have the value SG for the NUM feature in its CONCORD specification. This accords with Wechsler \& Zlatićs claim that noun-phrase-internal agreement depends on CONCORD features. The noun boy contributes both CONCORD and INDEX agreement information: the value of the NUM feature in both the INDEX and CONCORD specifications is SG. As Wechsler \& Zlatić demonstrate, feature values for CONCORD and INDEX often coincide, as in this example, though in many interesting cases the values of these two lexically-specified features may diverge. We do not examine pluralia and singularia tantum here; see Wechsler \& Zlatić (2000, 2003) on how these are encoded in the feature space.

For a noncoordinated noun phrase like this boy, the following configuration results.

this boy

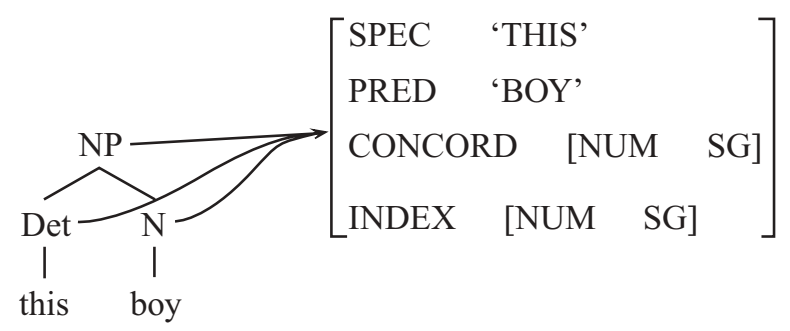

The relation between nodes in the constituent structure tree and the $\mathrm{f}$ structures they correspond to is represented by arrows from tree nodes to f-structures. In this case, the phrase structure rule in (6) requires that the three nodes NP, Det, and N all correspond to the same f-structure.

Thus, the determiner this requires the noun it combines with to have singular CONCORD agreement by the specification $(\uparrow$ CONCORD NUM) $=\mathrm{SG}$, which also appears on the noun boy. By virtue of the $\uparrow=\downarrow$ annotations on the phrase structure rule expanding NP, both of these specifications refer to the f-structure in (8), which has the value SG for the NUM feature in its CONCORD specification, as required. If the requirements specified by the noun and the determiner conflict, as in *this boys, the resulting f-structure specification has no solution, since the value for the NUM feature is required to be simultaneously SG (by the determiner) and PL (by the noun). This is not allowed, as these two values are incompatible.

For a plural phrase like these boys, the c-structure and f-structure are as in (I0). The relevant lexical entries are shown in (9); they are similar to those in (7), except for requiring a NUM value of PL. 
(9) these ( $\uparrow$ SPEC $)=$ 'THESE'

$(\uparrow \mathrm{CONCORD} N \mathrm{NUM})=\mathrm{PL}$

boys $\quad(\uparrow \mathrm{PRED})={ }^{\mathrm{B}} \mathrm{BOY}$ '

$(\uparrow \mathrm{CONCORD}$ NUM $)=\mathrm{PL}$

$(\uparrow$ INDEX NUM $)=\mathrm{PL}$

(Io) these boys

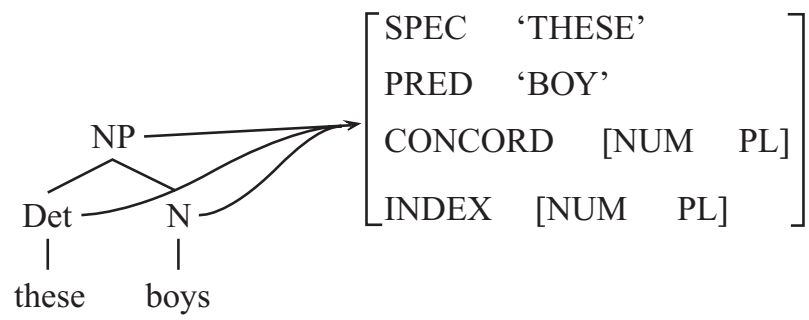

Here, the determiner and noun both require a PL value for the NUM feature in their CONCORD specification; these requirements are both satisfied in the $\mathrm{f}$-structure given in (Io).

\section{I Distributive and nondistributive features}

The English data in (I)-(4) above are easily accounted for by exploiting the LFG distinction between nondistributive and distributive features, originally proposed by Dalrymple \& Kaplan (2000). The distinction is important in the analysis of coordinate structures, which are represented by sets in LFG. A simplified functional structure for a coordinate phrase like Joe and Fred is given in (II).

(II)

$$
\text { if }\left\{\begin{array}{ll}
j: \text { [PRED } & \text { 'JOE'] } \\
f: \text { [PRED } & \text { 'FRED'] }
\end{array}\right\}
$$

Each conjunct corresponds to a member of the set representing the coordinate structure as a whole: the conjuncts labeled $j$ (for Joe) and $f$ (for Fred) are members of the set labeled $j f$, representing the coordinate phrase.

The phrase structure rule for noun coordination given in (I2) is an instance of the standard coordination rule in LFG (Kaplan \& Maxwell I988; Dalrymple 200I: chapter 9). ${ }^{3}$

$$
\begin{aligned}
& \mathrm{N} \rightarrow \mathrm{N} \text { Conj } \mathrm{N} \\
& \downarrow \in \uparrow \quad \uparrow=\downarrow \quad \downarrow \in \uparrow
\end{aligned}
$$

[3] To simplify presentation, the rule in (I2) has been modified to account only for coordinate structures with two conjuncts. For a more complete account of coordination in LFG, including coordinate structures with more than two conjuncts, see Dalrymple (200I : chapter 9). 
This rule specifies that the f-structure for each daughter node is a member of the set of f-structures associated with the mother node; this is accomplished by the $\downarrow \in \uparrow$ annotation on each daughter node. The annotation $\uparrow=\downarrow$ on the Conj node ensures that any relevant $\mathrm{f}$-structure features associated with the conjunction are also associated with the mother node. In the analysis of a phrase like Joe and Fred, this rule requires the f-structure for each conjunct Joe and Fred to be a member of $j f$, the f-structure set for the coordinate structure, as was shown in (II).

Some f-structural features are nondistributive, meaning that they can be associated with a set representing a coordinate structure as a whole, as well as with the individual members of the set. Other features are distributive, meaning that they can be associated only with the members of a set - the individual conjuncts - and not with the set as a whole. In (II), nondistributive features may be associated with the f-structure $j f$ for the entire coordinate structure, while distributive features are associated only with the conjuncts $f$ and $j$ and cannot appear as features of $j f$.

\section{I.I INDEX features}

We propose that INDEX features are nondistributive features. This means that the set representing a coordinate structure can have INDEX features representing the agreement features for the set. In particular, a coordinate structure is treated as plural by virtue of the presence of the PL value in its INDEX features, regardless of whether its conjuncts are plural or singular; even a coordinate phrase in which every conjunct is singular, like Joe and Fred, behaves as a plural phrase.

(I3) INDEX agreement with a coordinate phrase depends on the INDEX features of the coordinate phrase as a whole.

Of course, other INDEX agreement features besides NUM are also present. Dalrymple \& Kaplan (2000) propose a theory of feature resolution in coordinate structures that explains how the resolved PERSON and GENDER features for a coordinate structure are determined on the basis of the PERSON and GENDER features of the conjuncts. For example, a coordinated noun phrase bears a first person INDEX feature if its conjuncts are a first person phrase and a second person phrase.

(I4) [I-IPERS and you-2PERS $]_{1 \text { PERS }}$

In many languages, evidence that the coordinate phrase bears the first person feature comes from verb agreement; example (I5) is from Slovak (Corbett 1983: 178).

(I5) $\mathrm{Ja}$ a ty sme bratia. [I-IPERS and yOu-2PERS $]_{1 \text { PERS }}$ are-IPERS brothers '[I and you $]$-IPERS are brothers.' 
Similarly, the resolved GENDER feature of a coordinate phrase is determined on the basis of the GENDER features of the conjuncts. In the following Hindi sentence, the first conjunct is masculine and the second is feminine. The resulting GENDER for the coordinate phrase is masculine, as shown by verb agreement. ${ }^{4}$

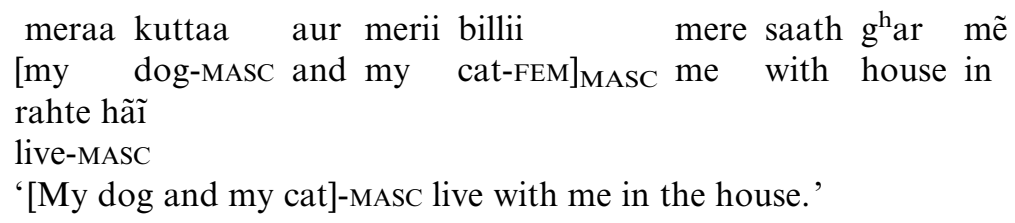

These resolved PERSON and GENDER features are also INDEX features and are associated with the coordinate phrase as a whole. Since our focus here is on the NUM feature, we will not provide further discussion of PERSON and GENDER features and how they are resolved in coordination. However, we predict that PERSON and especially GENDER constraints can be placed on possible coordination structures in a way similar to NUM. For example, some determiners may require that all the conjuncts have the same value for GENDER. For more discussion of PERSON and GENDER resolution in coordination, see Sadler (1999, 2003), Dalrymple \& Kaplan (2000), Vincent \& Börjars (2000), Wechsler (2002), and the references cited there.

In the present context, we are particularly interested in the value of the INDEX NUM feature of the coordinate phrase. In intuitive terms, the INDEX NUM feature of a phrase represents the number of individuals it refers to: a noun phrase has an SG value for INDEX NUM if it refers to one individual, and a PL value if it refers to more than one individual. Coordinate phrases usually refer to more than one individual; for example, a phrase like this boy and girl behaves like a plural phrase with a plural value for its INDEX NUM.

(I7) This boy and girl are eating a pizza.

In some cases, however, a coordinate phrase can refer to a single individual, as in my friend and colleague or the vice-president and president-elect. In such cases, the phrase behaves like a singular phrase with a singular value for its INDEX NUM.

(I8) The vice-president and president-elect is eating a pizza.

We propose that the semantic distinction between these two cases is tied to a syntactic distinction in INDEX NUM requirements. In particular, coordinate phrases like this boy and girl involve a 'group forming' interpretation of and, requiring, roughly, a group composed of boys and girls. This interpretation of and requires the noun phrase to have a plural value for its INDEX NUM feature.

[4] We are grateful to Miriam Butt for providing the example in (I6). 


\section{(I9) Group-forming and (this boy and girl)}

$(\uparrow \operatorname{INDEX} \mathrm{NUM})=\mathrm{PL}$

In contrast, coordinate phrases like my friend and colleague involve a boolean interpretation of and, requiring that the individual or individuals have each relevant property: for example, each individual that is referred to must be both a friend and a colleague. We will see below that many languages (e.g., German, Brazilian Portuguese) allow only this interpretation for coordinated nouns with a singular determiner (so that phrases like this boy and girl are disallowed), and some languages (e.g., Greek) allow only this interpretation for both singular and plural determiners with coordinated nouns (so that phrases like these boys and girls are also disallowed). With this interpretation of and, the INDEX NUM of the coordinate structure is required to be the same as the INDEX NUM of the conjuncts. ${ }^{5}$

(20) Boolean and (my friend and colleague)

$(\uparrow \operatorname{INDEX} \mathrm{NUM})=(\uparrow \in$ INDEX NUM $)$

This equation requires the INDEX NUM of the coordinate structure ( $\uparrow$ INDEX NUM) to be the same as the INDEX NUM of one of the conjunct phrases. We can refer to a member of the conjunct set using the notation ( $\uparrow \in$ INDEX NUM) where the set membership symbol $\in$ appears as an attribute. We also assume a semantic requirement (which we do not state explicitly here) that forces all of the conjuncts to have the same number. That is, we assume that a phrase like my friend and colleagues has no boolean interpretation because a singular noun like friend and a plural noun like colleagues cannot simultaneously describe the same entity.

\section{I.2 CONCORD features}

In contrast to the INDEX feature, CONCORD features are distributive, meaning that the set representing a coordinate structure has no CONCORD feature. Instead, the CONCORD feature is associated only with the individual conjuncts, the individual members of the set representing the coordinate structures. In other words, distributive features like CONCORD do not appear as features of a coordinate structure as a whole, and may only appear as features of the individual conjuncts.

The f-structure in (2I), for this boy and girl, illustrates the configuration we propose. The f-structures for the noun conjuncts boy and girl are labeled $b$ and $g$ respectively; each has both CONCORD and INDEX features with a number attribute NUM taking the value SG, as a result of the information in the lexical entries. Each of these f-structures is a member of the set associated with the coordinate phrase this boy and girl, labeled $c$. The members $b$ and $g$ of the set $c$ appear inside curly brackets.

[5] When the set-membership symbol $\in$ is used as an attribute, as in (20), it nondeterministically picks out one of the members of a set (Dalrymple 200I: I54). 
(2I) this boy and girl

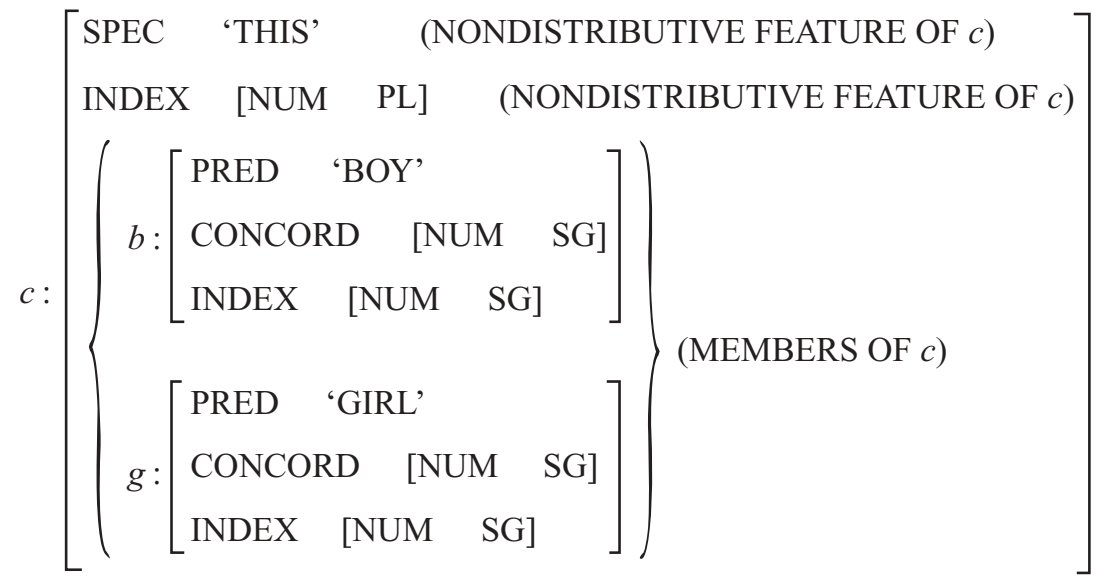

Besides the members $b$ and $g$, the set $c$ also has nondistributive features, which appear inside the enclosing square brackets. In (2I), $c$ has two nondistributive features: the SPEC feature with its value 'THIS', and the INDEX feature with the value [NUM PL]. No distributive feature may be associated with the set $c$. In particular, $c$ may not have a CONCORD feature.

As shown by Wechsler \& Zlatić (2000: 804), verb agreement in English depends on the value of the INDEX feature. When a phrase like this boy and girl appears as the subject of a sentence, its plural INDEX feature means that the verb is required to show plural agreement. Thus, a phrase like this boy and girl behaves like a plural phrase, requiring plural agreement with the verb in examples like those in (3) above: verb agreement refers to the INDEX features of the coordinate phrase $c$, not the INDEX or CONCORD features of the individual conjuncts $b$ and $g$.

We turn now to determiner agreement. In line with the theory proposed by Wechsler \& Zlatic (2000, 2003), an English determiner like this must be compatible with the CONCORD features of its phrase. Since the CONCORD feature is a distributive feature, it cannot be an attribute of a set: the set $c$ in example (2I) contains no CONCORD feature. How, then, is a distributive feature of a coordinate structure licensed?

Dalrymple \& Kaplan (2000) show that any requirement that holds of a distributive feature of a set must hold of each member of the set. In particular, if the set $c$ in (2I) is required by the determiner to have singular CONCORD, then each member of $c$ must have singular concord.

(22) CONCORD agreement with a coordinate phrase depends on the CONCORD features of each conjunct.

When a singular determiner appears with coordinated nouns like boy and girl, the set $c$ representing the coordinate phrase boy and girl is required to 
have singular CONCORD. Since CONCORD is a distributive feature, this means that the NUM feature in the CONCORD specification for each member of the coordinate phrase must be licensed to make sure that it is singular. This requirement holds of each conjunct $b$ and $g$ in example (2I), and the example is well-formed.

Dalrymple \& Kaplan (2000) give the following more formal definition of when distributive and nondistributive properties hold of sets.

(23) For any distributive property $P$ and set $s, P(s)$ iff $\forall f \in s . P(f)$.

For any nondistributive property $P$ and set $s, P(s)$ iff $P$ holds of $s$ itself.

This definition simply restates the more intuitive characterizations given above. If a nondistributive property (such as having a plural INDEX value) holds of a set, it must hold of the set itself; if a distributive property (such as having a singular CONCORD value) holds of a set, it must hold of each member of the set.

\subsection{Agreement and coordination}

In this section, we show in detail how several English examples are analyzed. We first look at coordinated singular nouns, then coordinated plurals, and finally mixed coordination of singular and plural nouns.

\subsection{Coordinated singular nouns}

For a coordinate structure like this boy and girl, the desired result is obtained straightfowardly - no extra assumptions are needed.

(24) this boy and girl

this: $(c$ CONCORD NUM) $=\mathrm{SG}$

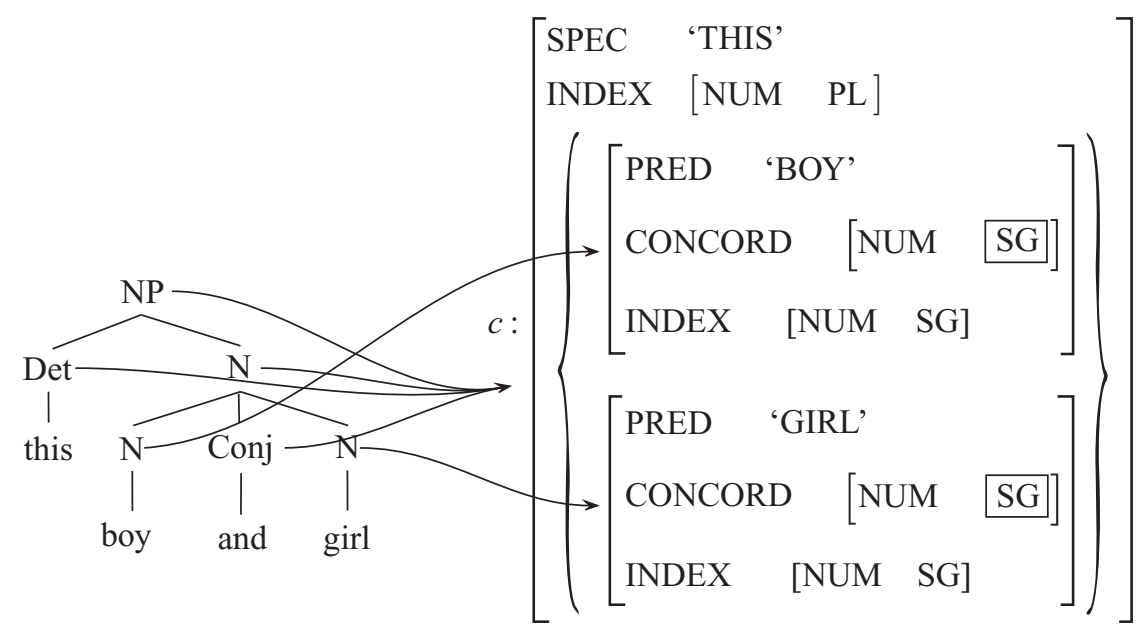


The demonstrative determiner this requires the value of the CONCORD feature of its f-structure $c$ to be SG. Since $c$ is a set and CONCORD is a distributive feature, the only way for this requirement to be satisfied is for each conjunct - each member of $c$-to have a singular CONCORD feature. This requirement is satisfied in (24), as shown by the boxed values of the NUM feature. However, the INDEX feature of the conjoined NP is PL, and hence the NP triggers plural verb agreement.

(25) This boy and girl are eating a pizza.

In contrast, a plural determiner like these is not compatible with conjoined singular nouns.

(26) *these boy and girl

these: $(c$ CONCORD NUM $)=\mathrm{PL}$

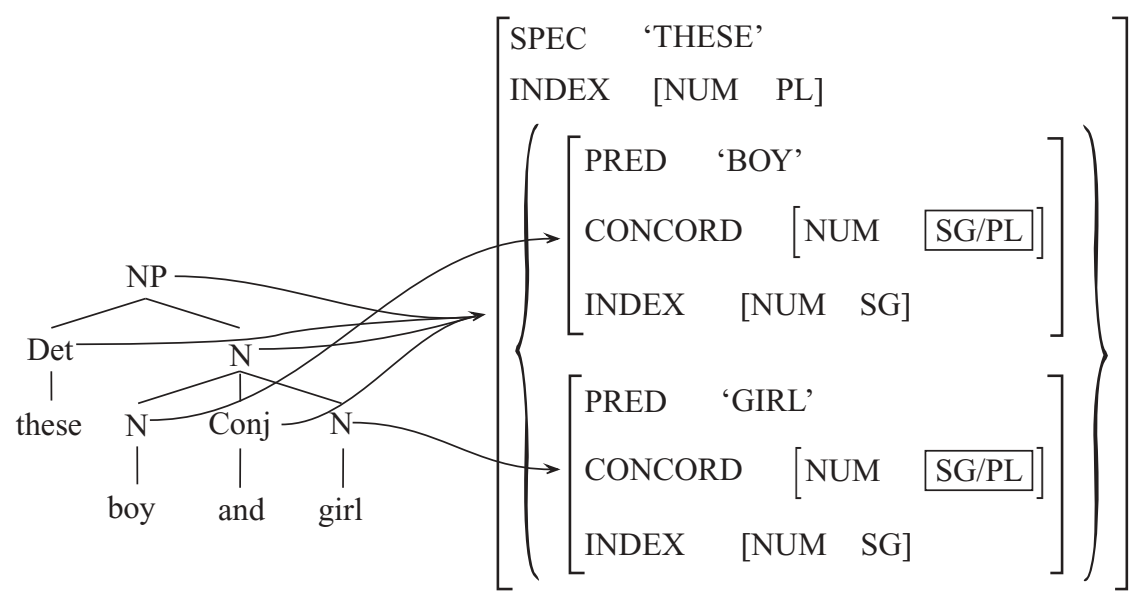

As the boxed values indicate, the example is ill-formed because of the incompatible requirements placed by the plural determiner these: these requires plural concord on each conjunct, but the singular nouns boy and girl each carry a singular concord feature.

\subsubsection{Coordinated plural nouns}

We now turn to the analysis of coordinated plural nouns. Consider the noun phrase these boys and girls and its corresponding c- and f-structures in (27). 
(27) these boys and girls these: $(c$ CONCORD NUM $)=\mathrm{PL}$

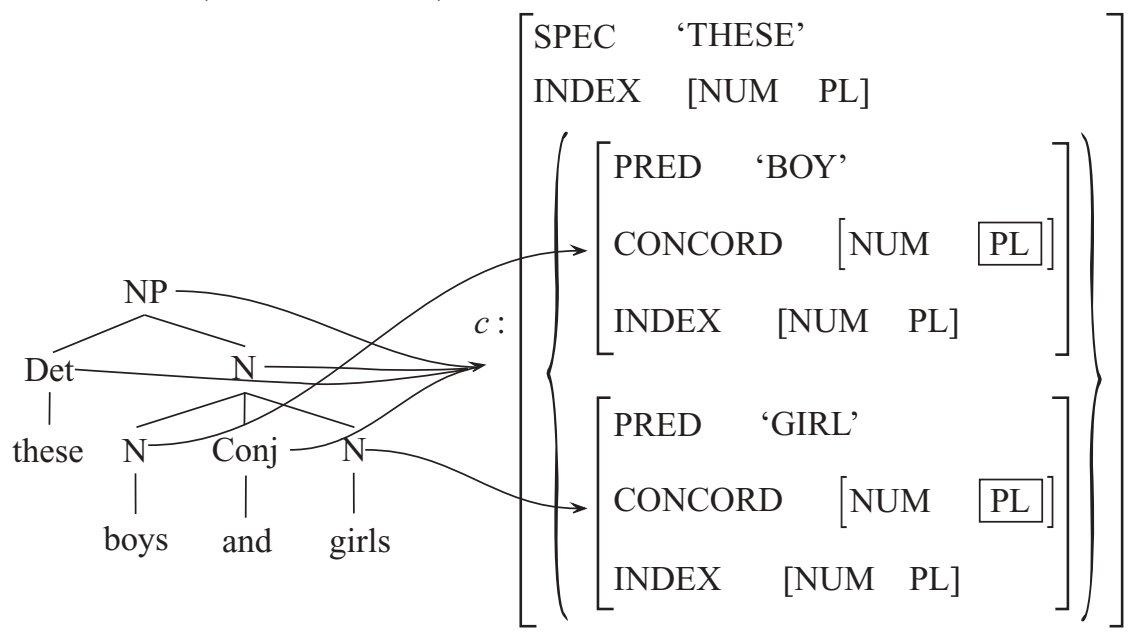

Each noun contributes CONCORD and INDEX features with PL values, as was seen in the lexical entries in (9). In addition, these requires $c$ to have a distributive CONCORD value of PL. This CONCORD NUM PL value is distributed to each member of the coordinate set and, correctly, is compatible with the CONCORD value provided by the nouns.

This contrasts with the situation in (28), involving the ungrammatical noun phrase *this boys and girls. In (28) the CONCORD NUM SG value provided by this distributes to each member of the coordinate set. However, it is incompatible with the CONCORD NUM PL values provided by the lexical entries of the nouns. As a result, the noun phrase is ill-formed.

*this boys and girls

this: $(c$ CONCORD NUM $)=\mathrm{SG}$

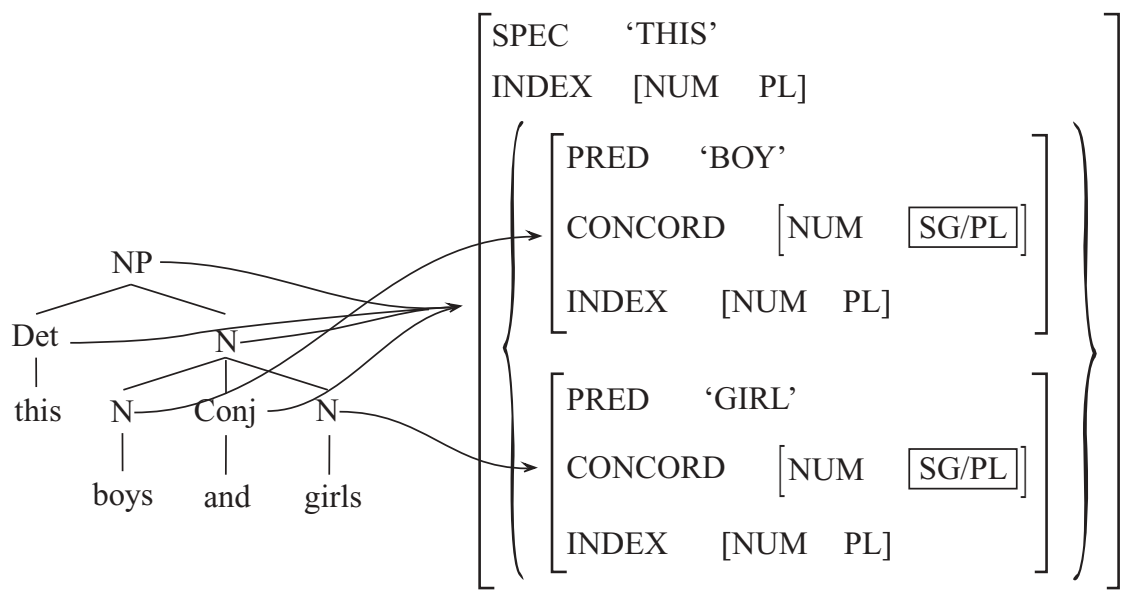




\subsubsection{Mixed coordinations: singular and plural nouns}

Having seen how coordinated singular nouns and coordinated plural nouns behave, we now consider mixed coordinations in which one noun is singular and one plural. With mixed coordinations, one conjunct has PL CONCORD and INDEX features, while the other has SG CONCORD and INDEX features. When these coordinated nouns appear with a determiner which requires SG CONCORD, this SG feature is incompatible with the PL conjunct, and the resulting structure is ungrammatical. This is because the requirements on the distributive CONCORD feature must be satisfied by all the conjuncts, as indicated in (29).

(29) *this [boy and girls] (ungrammatical with structure as indicated)

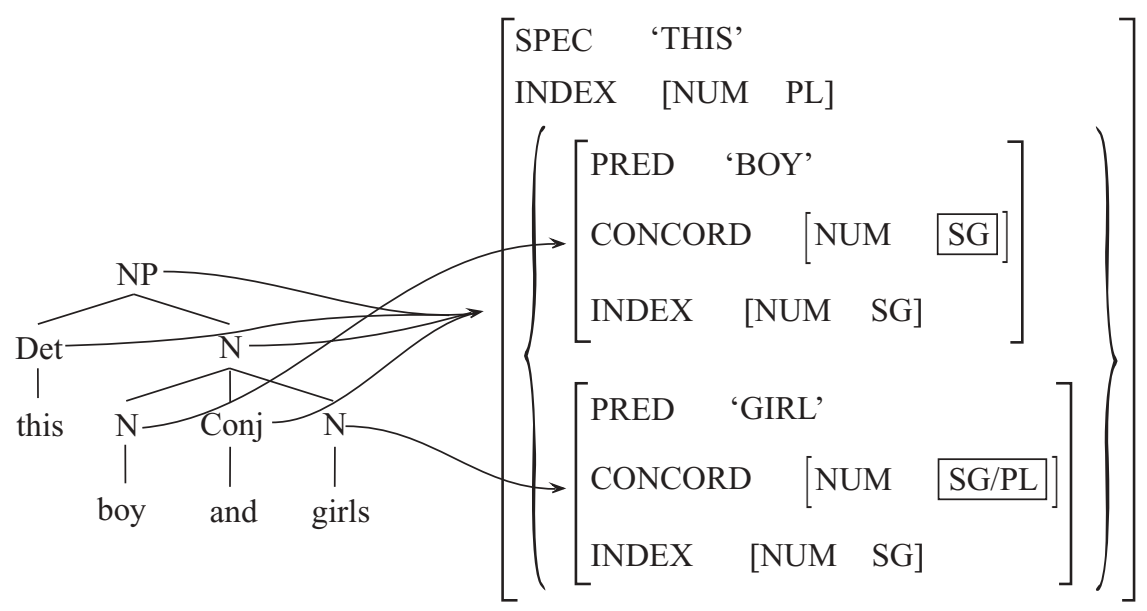

Similarly, plural determiners are disallowed with mixed coordinate structures because they are incompatible with a singular conjunct.

However, it turns out that some determiners do not specify a CONCORD value for their phrase. For example, either singular or plural nouns can be used with the English determiners the and $m y$.

(30) (a) the boy/the boys

(b) my friend/my friends

With such determiners, mixed singular/plural coordinations are possible, since the determiner does not constrain the CONCORD value of the conjuncts. Some naturally occurring examples are shown in (3I) and (32). Such examples are extremely common, and many more such examples can be found. In (3I) the first conjunct is singular and the second plural, while in (32) the first conjunct is plural and the second is singular. In each case, one CONCORD feature is SG and one PL. The INDEX feature of the coordinated set is PL, as reflected by the plural verb agreement in the examples. 
(3I) (a) [The animal action consists of a cat and two poodles.] The cat and dogs are seen throughout the film doing various behavioral stunts.

(http://www.ahafilm.info/movies/moviereviews.phtml?fid=7095)

(b) The man and boys were walking down Maryhill Road in Glasgow when the boys ran away in front, leaving him holding the family dog on a leash.

(http://news.bbc.co.uk/hi/english/uk/newsid_354000/35483I.stm)

(c) My dog and cats eat poultry bones every day.

(www.critterchat.net/feedingnat.htm)

(32) (a) [We have two dogs, one kitten, a lizard, and assorted fish.] The dogs and cat are all rescues, from the street or the pound.

(http://www.gmee.com/pets/about.html)

(b) [A boy went out to check on his pigs ... and ran back to the farmhouse to get his father, who was there with some other men.] The men and boy returned to the area in their pickups with weapons.

(http://www.n2.net/prey/bigfoot/stories/woodward.htm)

(c) I enjoy collecting children's literature and playing with my dogs and cat: Lucy, Desi and Smokey.

(http://www.mcps.org/fbranch/200ofirst/burnette.html)

A lexical entry for the determiner the is shown in (33). Unlike this, in (7), and these, in (9), no CONCORD value is specified; the can be used with singular nouns, plural nouns, or any coordinate structure.

(33) the $(\uparrow \mathrm{SPEC})={ }^{\prime} \mathrm{THE}$ '

Since no CONCORD value is specified, there is nothing to be distributed to the conjuncts. As a result, one conjunct can be singular and the other plural, as in the example in (34). Note that the PL INDEX value results in plural verb agreement, as in (35).

(34) the dogs and cat

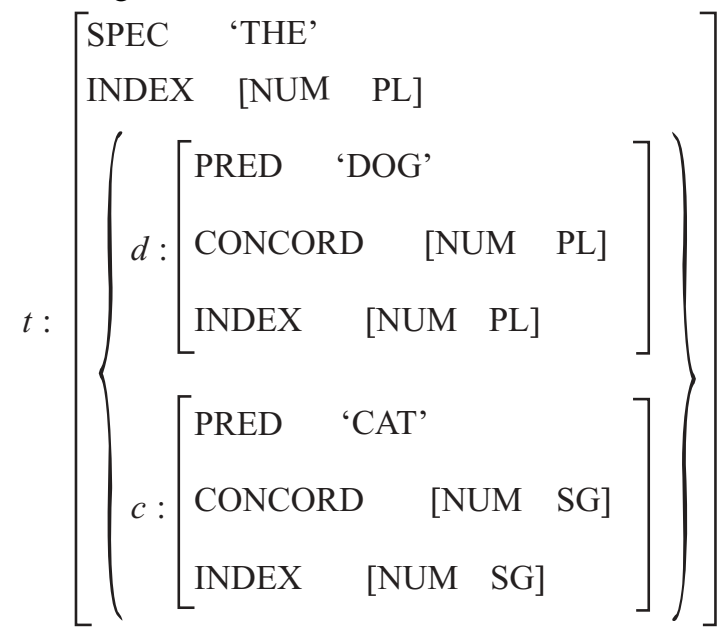


(35) The dogs and cat were inoculated yesterday.

\section{NP-internal agreement: other predicted patterns}

Having seen how NP-internal agreement works in English, we now explore the analysis of languages with different NP-internal agreement patterns. On our view, both the CONCORD and INDEX features are in principle available for NP-internal agreement, and so we would expect some languages to allow INDEX rather than CONCORD agreement (contra the claims of Wechsler \& Zlatic 2000, 2003). As we will see, this expectation is borne out: some determiners require only INDEX agreement, some only CONCORD, and some both INDEX and CONCORD agreement.

\section{I Possible agreement patterns}

In principle, determiners can require CONCORD agreement, INDEX agreement, both, or neither. In a very interesting exploration of the syntax of determiners and modifiers of conjoined nouns, Plank (I99I) notes a three-way distinction in agreement patterns. To restate his findings in our terms: in some cases, agreement is with the CONCORD features of the conjuncts, as for English this and these; in some cases, agreement is with the resolved INDEX features of the full coordinate phrase; and in some cases, agreement is with a distinguished conjunct, as in closest-conjunct agreement. Putting aside closestconjunct agreement and concentrating on cases of agreement with the coordinate structure as a whole, our analysis predicts the agreement patterns for determiners given in $(36){ }^{6}$

(36) (a) Determiners with no agreement restrictions: allowed with singular nouns, conjoined singulars, plural nouns, conjoined plurals, and conjoined nouns with one singular and one plural conjunct.

(b) Determiners requiring singular (SG) INDEX: allowed with nonconjoined singular nouns and conjoined singular nouns which refer to a single individual (such as in my friend and colleague or the vicepresident and president-elect); impossible with conjoined or plural nouns which refer to more than one individual.

(c) Determiners requiring singular (SG) CONCORD: allowed with singular nouns and conjoined singular nouns, where each conjunct has singular CONCORD, but disallowed with plural nouns or with any coordinate structure with one or more plural conjuncts.

(d) Determiners requiring singular (SG) INDEX and CONCORD: same as requirements for singular INDEX $(=(b)$ above), since the INDEX requirements pick out a strict subset of the environments constrained by the CONCORD feature.

[6] We thank an anonymous $J L$ referee for very useful comments on this section. 
(e) Determiners requiring plural (PL) CONCORD: allowed only with plural nouns and conjoined plural nouns, in which the CONCORD value of each conjunct is plural; disallowed with any coordinate structure with a singular conjunct.

(f) Determiners requiring plural (PL) INDEX: allowed with plurals and with any type of conjunction referring to more than one individual; disallowed only when a single individual is referred to.

(g) Determiners requiring plural (PL) INDEX and CONCORD: same as requirements for plural CONCORD $(=(\mathrm{e})$ above), since the CONCORD requirements pick out a strict subset of the environments constrained by the INDEX feature.

In principle, there is another type of determiner: one that requires singular CONCORD and plural INDEX. Such a determiner could be used with coordinate structures referring to more than one individual in which each conjunct is singular. We rule these out by requiring determiners to impose uniform number specifications: there are no determiners that impose a different value for CONCORD and INDEX. ${ }^{7}$ Note that this is unlike the case for the intrinsic specification of nouns, which may demonstrate mismatched CONCORD and INDEX values. In this paper, we do not investigate how such nouns behave in coordinate structures, leaving this for future work. However, our analysis makes clear predictions for such nouns: determiners which have requirements on CONCORD values will have to agree with the CONCORD value of the noun, regardless of its INDEX value; determiners which have requirements on INDEX will agree with the INDEX of the coordinate structure, regardless of the INDEX of the noun itself.

Restating these results in tabular form, we have:

\begin{tabular}{llllll}
\hline Requirements & $\begin{array}{l}\text { Singular } \\
\text { noun }\end{array}$ & $\begin{array}{l}\text { Conj. } \\
\text { singulars }\end{array}$ & $\begin{array}{l}\text { Mixed } \\
\text { coord. }\end{array}$ & $\begin{array}{l}\text { Conj. } \\
\text { plurals }\end{array}$ & $\begin{array}{l}\text { Plural } \\
\text { noun }\end{array}$ \\
\hline No restrictions (36a) & $\sqrt{ }$ & $\sqrt{ }$ & $\sqrt{ }$ & $\sqrt{ }$ & $\sqrt{ }$ \\
SG CONCORD (36c) & $\sqrt{ }$ & $\sqrt{ }$ & $*$ & $*$ & $*$ \\
SG INDEX (and & $\sqrt{ }$ & $(*)$ & $*$ & $*$ & $*$ \\
$\quad$ CONCORD) (36b, d) & & & & & \\
PL CONCORD (and & $*$ & $*$ & $*$ & $\sqrt{ }$ & $\sqrt{ }$ \\
$\quad$ INDEX) (36e, g) & & & & & $\sqrt{ }$ \\
PL INDEX (36f) & $*$ & $\sqrt{ }$ & $\sqrt{ }$ & $\sqrt{ }$ & $\sqrt{ }$ \\
\hline
\end{tabular}

The parentheses around the asterisk in the 'conjoined singulars' column for the 'singular index and concord' agreement constraint represent the fact that

[7] We thank an anonymous $J L$ referee for suggesting this restriction. At this point, we stipulate this requirement. However, in future research we hope to derive this restriction from other properties of the agreement system. 
the only coordinate examples that are allowed are those in which the conjuncts refer to a single individual, examples such as my friend and colleague.

Based on these patterns, we propose a typology of crosslinguistically available agreement systems, defined by the parameters of our proposal. Our account allows four possible kinds of agreement systems, depending on whether agreement is constrained in terms of the INDEX feature, the CONCORD feature, neither feature, or both features. Note that different determiner systems within the same language might behave differently: in English, for example, the demonstrative determiner system distinguishes singular (this/ that) from plural (these/those), while the definite determiner system consists of a single determiner, the, which does not distinguish number.

We first consider the least restricted pattern, exemplified by the top row of the table. If the same form is used for both singular and plural nouns, it places no restrictions on the number of the noun it combines with, and barring other restrictions (such as gender marking) should also work with all coordinate cases, including mixed coordination. As we have seen, this is the case of English the. We show below that the Georgian determiner es 'this/ these' and the Armenian demonstrative determiners ais/aid 'this/these/that/ those' also exemplify this pattern.

Next, we consider determiner systems in which number agreement plays a role; such systems have separate singular and plural determiners. There are several possibilities.

In the first type of system, both INDEX and CONCORD requirements are imposed. This is the most restrictive system, imposing INDEX agreement (and, redundantly, CONCORD agreement) in the singular case, and CONCORD agreement (and, redundantly, INDEX agreement) in the plural case. ${ }^{8}$ The singular determiner cannot be used with coordinated nouns whose INDEX is plural; it is compatible only with singular nouns and coordinated singular nouns that refer to a single individual, i.e. phrases like my friend and colleague. The plural determiner can be used only with plural nouns and conjoined plurals, but not with coordinations in which one or more conjuncts are singular. Determiner sharing is not allowed with conjoined singular nouns referring to more than one person, or with mixed singular/plural coordinate structures. As we will see, determiners in Brazilian Portuguese and German exemplify this system.

(38) CONCORD and INDEX systems: Brazilian Portuguese, German

(a) Singular determiner:

$(\uparrow \mathrm{CONCORD} N \mathrm{NUM})=\mathrm{SG}$

$(\uparrow$ INDEX NUM $)=S G$

(b) Plural determiner:

$(\uparrow$ CONCORD NUM $)=\mathrm{PL}$

$(\uparrow$ INDEX NUM $)=P L$

[8] This corresponds to a subset of Type A in Plank's I99I typology. 
Note that (38a) reduces to SG INDEX and (38b) reduces to PL CONCORD. However, the determiners must have both sets of features, as listed in (38), in order to form a well-formed system whereby the determiners differ only in the NUM value, not in the set of agreement features specified.

The second type of system involves CONCORD features only, not INDEX features. ${ }^{9}$ The singular determiner may be used with singular nouns and with coordinate structures in which each conjunct is singular. The plural determiner may be used with plural nouns and with coordinate structures with plural conjuncts. In these systems, determiner sharing is not allowed with mixed singular/plural coordinate structures. In coordinate structures with uniform number, the determiner is used which would be used in the noncoordinate case: the singular determiner is used with conjoined singular nouns, and the plural determiner is used with conjoined plurals. This system is exemplified by the English demonstrative determiner system (this/these, that/those). We will see that Finnish and Hindi/Urdu determiners also follow this pattern.

(39) CONCORD systems: Finnish, Hindi/Urdu

(a) Singular determiner:

$(\uparrow \mathrm{CONCORD}$ NUM $)=\mathrm{SG}$

(b) Plural determiner:

$(\uparrow$ CONCORD NUM $)=\mathrm{PL}$

Finally, determiner systems can refer exclusively to INDEX features. Such systems are crosslinguistically less common: in the unmarked case, agreement inside the noun phrase refers to CONCORD features, as Wechsler \& Zlatić propose. Systems in which agreement features are relevant, but only INDEX features are constrained, are relatively rare. However, such systems are attested, and we will show that Russian determiners exemplify this system. INDEX systems are unique in allowing plural determiners with coordinated singular nouns. Such systems also disallow coordinated singular nouns with singular determiners except when a single individual is referred to, as in Brazilian Portuguese and German. In such systems, only the INDEX value is constrained.

(40) INDEX systems: Russian

(a) Singular determiner:

$(\uparrow \operatorname{INDEX} \mathrm{NUM})=\mathrm{SG}$

(b) Plural determiner:

$(\uparrow$ INDEX NUM $)=\mathrm{PL}$

These four types of systems exhaust the possible types of determiner systems. A number of types of determiners that are possible in theory are

[9] This corresponds to Type B in Plank's I99I typology. 
excluded by this typology, such as: determiner systems with a special form for all coordinate structures, regardless of the resulting INDEX value; systems with a form that is used with noncoordinated plurals and coordinated singulars, but not coordinated plurals; and systems with a special form for coordinated plurals that is not used for noncoordinated plurals. To our knowledge, no such systems are attested, and we believe it is a virtue of our theory that they are predicted not to exist.

In the next sections, we examine these possibilities as illustrated by several different languages. As we will see, all of the possible agreement patterns predicted by our analysis are attested. Furthermore, we have found no attested instances of patterns which do not fall within one of these four systems.

\subsection{No number specifications: Georgian and Armenian}

As described in section 2.2.3, the English determiner the specifies neither CONCORD nor INDEX features. As such, it can occur with either singular or plural noncoordinated nouns, as well as with conjoined singulars, conjoined plurals, and mixed coordinations.

The same is true for the Georgian proximal demonstrative es 'this/these', which is unspecified for number. ${ }^{10}$ Es can be used with singular and plural nouns, as shown in (4I).

(4I) (a) es masçavlebeli

this teacher-sG

'this teacher'

(b) es masçavleblebi

this teacher-PL

'these teachers'

(42) shows that es is compatible with all coordinations: singular coordinations, as in (42a), plural coordinations, as in (42b), and mixed singular/ plural coordinations, as in (42c) and (42d).

(42) (a) es masçavlebeli da moçape

this teacher-sG and pupil-sG

'this teacher and pupil'

(b) es masçavleblebi da moçapeebi

this teacher-PL and pupil-PL

'these teachers and pupils'

(c) es masçavlebeli da moçapeebi

this teacher-sG and pupil-PL

'this/these teacher and pupils' (= 'this teacher and these pupils')

[Io] Georgian is a member of the South Caucasian language family (Grimes I999). Thanks to Manana Mgeladze for the Georgian data. 
(d) es masçavleblebi da moçape

this teacher-PL and pupil-sG

'this/these teachers and pupil'

The f-structure for the mixed singular/plural coordination example in (42c) is similar to that in (34) above for English. As with English the, the behavior of es can be accounted for if the lexical entry for es does not specify any INDEX or CONCORD number information, as in (43). This information is compatible with any INDEX and CONCORD specifications of coordinated or noncoordinated nouns.

(43) es $\quad(\uparrow \mathrm{SPEC})={ }^{\prime} \mathrm{ES}$ '

The Armenian demonstrative determiners ais 'this/these' and aid 'that/ those' are also unmarked for number, and behave similarly to the Georgian determiner es 'this/these'. ${ }^{11}$ The lexical entries for these determiners are similar to the one for the Georgian determiner: no INDEX or CONCORD features are specified. Example (44a) shows that ais 'this/these' can be used with coordinated singular nouns; example (44b) shows that it can be used with coordinated plural nouns; and examples $(44 \mathrm{c}, \mathrm{d})$ illustrate its use with coordinations in which one conjunct is a singular noun and the other is a plural noun. The determiner aid 'that/those' can also be used in all of these constructions.

(44) (a) ais t'gha-mardh u kin

this man-sG and woman-sG

'this man and woman'

(b) ais t'gha-mardhik u kanajts

this men-PL and women-PL

'these men and women'

(c) ais t'gha-mardh u kanajts

this man-SG and women-PL

'this/these man and women'

(d) ais t'gha-mardhik $u$ kin

this men-PL and woman-SG

'this/these men and woman'

These determiners exemplify the most unconstrained pattern of determiner agreement: no agreement restrictions are imposed, and the determiners can be used with singular and plural nonconjoined nouns as well as with all types of coordinate structures.

[II] Armenian is the sole member of the Armenian subfamily of Indo-European (Grimes I999). We thank Irene Hayrapetian and Albert Badalian for their help with the Armenian data. 


\section{$3 \cdot 3$ CONCORD systems: Finnish and Hindi/Urdu}

Determiner systems which impose CONCORD agreement requirements are exemplified by the English demonstrative determiners this/these and that/those. Such determiner systems are also found in Finnish and Hindi/Urdu. ${ }^{12}$

We first consider the Finnish singular demonstrative determiner tämä 'this'. It can, of course, be used with singular nouns.

(45) tämä kissa

this-SG cat-SG

'this cat'

Tämä can also be used with conjoined singular nouns, as in (46a), but not with conjoined plurals, as in (46b), or with mixed coordinations, as in (46c).

(46) (a) tämä kissa ja koira

this-SG cat-SG and dog-SG

'this cat and dog'

(b) *tämä kissat ja koirat this-SG cat-PL and dog-PL

('this cats and dogs')

(c) *tämä [kissa ja koirat] this-SG cat-SG and dog-PL

('this cat and dogs') (ungrammatical with structure as indicated)

As with the English demonstrative determiner this, these facts can be accounted for if the lexical entry for tämä is as in (47), requiring singular CONCORD.

(47) tämä

$$
\begin{aligned}
& (\uparrow \mathrm{SPEC})={ }^{\prime} \mathrm{TÄM} \ddot{A} ’ \\
& (\uparrow \text { CONCORD NUM })=\mathrm{SG}
\end{aligned}
$$

The SG CONCORD feature distributes to each conjunct and is compatible only with other SG CONCORD values. If one or both of the conjuncts have PL CONCORD, the values are not compatible, and the result is ungrammaticality. The f-structure for (46a) is similar to that in (2I) above for English.

The plural counterpart of tämä 'this', the plural demonstrative determiner nämä 'these', also exhibits CONCORD agreement. Nämä can modify plural nouns, as in (48a), conjoined plural nouns, as in (48b), but not conjoined singulars, as in (48c), or mixed coordinations, as in (48d) on the indicated bracketing.
(a) nämä kissat
these-PL cats-PL
'these cats'

[12] Finnish is a member of the Uralic language family, and Hindi/Urdu is a member of the IndoAryan group of Indo-European (Grimes 1999). Thanks to Lauri Karttunen for the Finnish data and to Vineet Gupta, Miriam Butt, and Tara Mohanan for the Hindi/Urdu data. 
(b) nämä kissat ja koirat these-PL cats-PL and dogs-PL 'these cats and dogs'

(c) *nämä kissa ja koira these-PL cat-SG and dog-SG ('these cat and dog')

(d) *nämä [kissat ja koira] these-PL cat-PL and dog-SG ('these cats and dog') (ungrammatical with structure as indicated)

As with the English plural demonstrative these, these facts can be accounted for if the lexical entry for nämä is as in (49).

(49) $n \ddot{a} m \ddot{a} \quad(\uparrow \mathrm{SPEC})=$ 'NÄM $\mathrm{A}$ '

$$
(\uparrow \text { CONCORD NUM })=\mathrm{PL}
$$

The PL CONCORD feature distributes to each conjunct and is compatible only with other PL CONCORD values. If one or both of the conjuncts have SG CONCORD, the values are incompatible and the result is ungrammaticality. The resulting structure must also have PL INDEX, which follows from the presence of conjuncts with plural CONCORD. The f-structure for ( $48 b)$ is similar to that in (27) above for English.

A similar situation obtains in Hindi/Urdu. As shown in (50), the determiner wah 'that' requires singular CONCORD. It can be used with coordinated singular nouns, but not with coordinations with one or more plural conjuncts.

(50) (a) wah bakraa

that-SG goat-M.SG

'that goat'

(b) wah bakraa aur kuttaa

that-SG goat-M.SG and dog-M.SG

'that goat and dog'

(c) *wah bakre aur kutte

that-SG goat-M.PL and dogs-M.PL

('that goats and dogs')

(d) *wah [bakraa aur kutte]

that-SG goat-M.SG and dogs-M.PL

('that goat and dogs') (ungrammatical with structure as indicated)

Like its Finnish and English plural counterparts, the Hindi/Urdu plural determiner we 'those' requires plural CONCORD. As shown in (5I), it is acceptable with plural nouns, (5Ia), and with coordinations in which each conjunct is plural, $(5 \mathrm{Ib})$, but not with coordinations containing a singular conjunct, (5IC, d). 
(5I) (a) we bakre

those-PL goat-M.PL

'those goats'

(b) we bakre aur kutte

those-PL goat-M.PL and dog-M.PL

'those goats and dogs'

(c) *we bakraa aur kuttaa

those-PL goat-M.SG and dog-M.SG

('those goat and dog')

(d) *we [bakre aur kuttaa]

those-PL goat-M.PL and dog-M.SG

('those goats and dog') (ungrammatical with structure as indicated)

\subsection{INDEX and CONCORD systems: Brazilian Portuguese and German}

Systems which impose both INDEX and CONCORD requirements are the most restrictive systems. Such systems are found in Brazilian Portuguese and German. $^{13}$

The singular determiner in INDEX/CONCORD systems requires the noun it combines with to have an SG value for INDEX, and, redundantly, an SG value for CONCORD. Such determiners are used in phrases referring to a single individual. Thus, they can be used with a nonconjoined singular noun, but not in general with conjoined nouns, unless the conjoined nouns refer to a single individual. They also may not be used with plural nouns or coordinations involving a plural noun.

The Brazilian Portuguese singular determiner $o$ 'the' can modify a singular noun, as in (52a). However, it cannot modify conjoined singulars referring to more than one individual, as in (52b); instead, the determiner must be repeated for each conjunct, as in $(52 \mathrm{c}) .{ }^{14}$

(52) (a) o cachorro

the-M.SG dog-M.SG

'the dog'

(b) $*_{\mathrm{o}} \quad$ cachorro e gato

the-M.SG dog-M.SG and cat-M.SG

('the dog and cat')

(c) $\mathrm{o}$ cachorro e gato

the-M.SG dog-M.SG and the-M.SG cat-M.SG

'the dog and the cat'

[13] Thanks to Valeria de Paiva for the Brazilian Portuguese data and to Miriam Butt and Stefan Riezler for the German data.

[14] Munn (2000) claims that Brazilian Portuguese determiners show closest-conjunct agreement, but this is not borne out in the dialect of our informant; example (52b) should be grammatical if closest-conjunct agreement is at work. 
It might be thought that syntactic constraints, e.g. on the phrase structure, preclude such configurations in which a determiner appears with coordinated nouns; however, such structures are in fact permissible, but only if the agreement constraints imposed by the determiner are met. In particular, since the determiner $o$ requires a singular INDEX value, our analysis predicts that such structures are possible with coordinate phrases just in case they refer to a single individual. This is in fact the case, as example (53) shows.

$$
\begin{aligned}
& \text { o presidente e diretor da Air France } \\
& \text { the-M.SG president-M.SG and director-M.SG of Air France } \\
& \text { 'the president and director of Air France' }
\end{aligned}
$$

Examples such as these clearly show that it is the INDEX feature that is relevant for determining the distribution of the determiner $o$, not the presence or absence of a coordinate structure.

Under our analysis, the simplified ${ }^{15}$ lexical entry for $o$ is as in (54).

$$
\begin{aligned}
& (\uparrow \mathrm{SPEC})={ }^{\prime} \mathrm{O} ’ \\
& (\uparrow \mathrm{CONCORD} N \mathrm{NUM})=\mathrm{SG} \\
& (\uparrow \mathrm{INDEX} N \mathrm{NUM})=\mathrm{SG}
\end{aligned}
$$

When $o$ is used with conjoined nouns that denote a pair of individuals, like cachorro e gato 'dog and cat', the determiner's INDEX NUM SG requirement is not compatible with the INDEX NUM PL value of the coordinate structure, and the result is ungrammatical. The f-structure for $(52 b)$ is shown in (55).

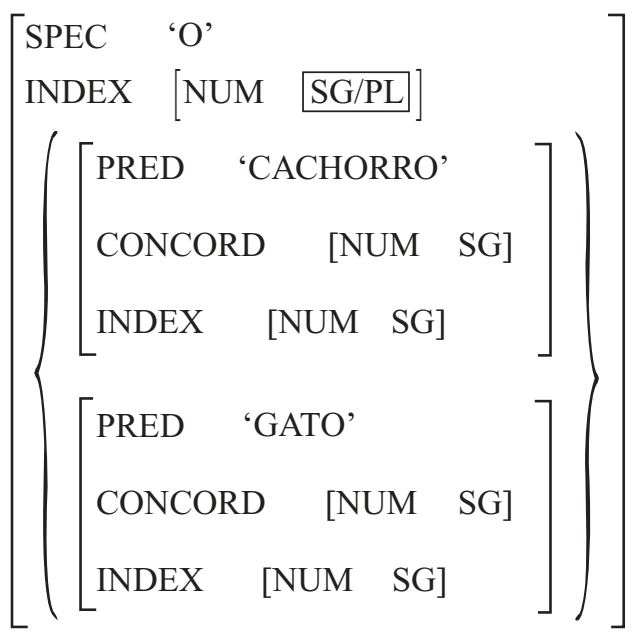

[15] We have omitted information about a number of features, including gender, which may place additional constraints on possible coordinations; see fn. I6. 
In contrast, $o$ is acceptable with conjoined nouns that have a singular index, like presidente e diretor (da Air France) 'president and director (of Air France)'.

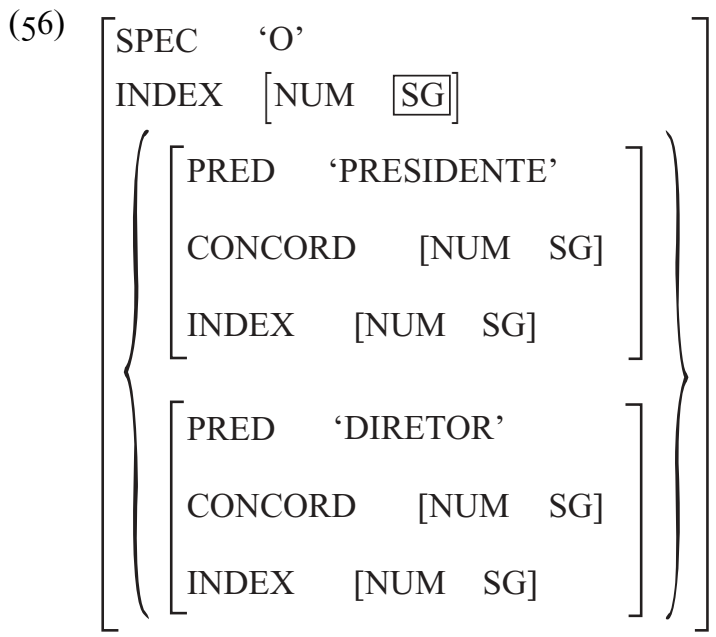

A similar situation is found in German: the German singular determiners mein 'my' and der 'the' are acceptable with conjoined nouns with an INDEX value of SG, where the conjoined nouns refer to the same individual: ${ }^{16}$
(a) mein bester Freund und Mann
my-M.SG best friend-M.SG and husband-M.SG
'my best friend and husband'
(b) der Präsident und Vorsitzende
the-M.SG president-M.SG and chairman-M.SG
'the president and chairman'

As in Brazilian Portuguese, this construction is possible only when the conjoined noun phrases refer to a single individual. When the index value is PL, the determiner cannot be shared, as shown in (58a). Instead, the determiner must be repeated, as in (58b).
[I6] Gender requirements rule out some examples of this type. Example (i) is ungrammatical because the masculine gender requirements of the determiner mein conflict with the femi- nine gender of the second conjunct Frau 'wife'.
(i) *mein bester Freund und Frau
my-M.SG best friend-M.SG and wife-F.SG
('my best friend and wife')


(b) der Hund und der Kanarienvogel the-M.SG dog-M.SG and the-M.SG canary-M.SG 'the dog and the canary'

Turning to the plural counterparts of these determiners, we find that the Brazilian Portuguese plural determiner os 'the' requires plural INDEX and CONCORD agreement. It can be used with plural nouns or conjoined plural nouns, but not with mixed coordinate structures.

(59) (a) os cachorros

the-M.PL dogS-M.PL

'the dogs'

(b) os cachorros e gatos

the-M.PL dogs-M.PL and cats-M.PL

'the dogs and cats'

(c) *os cachorro e gato

the-M.PL dog-M.SG and cat-M.SG

('the dog and cat')

(d) *os cachorros e gato

the-M.PL dog-M.PL and cat-M.SG

('the dogs and cat')

Similar patterns hold for the German plural determiner die 'the'.

(6o) (a) die Hunde

the-M.PL dogs-M.PL

'the dogs'

(b) die Hunde und Kanarienvögel

the-M.PL dogS-M.PL and canaries-M.PL

'the dogs and canaries'

(c) *die Hund und Kanarienvogel

the-M.PL dog-M.SG and canary-M.SG

('the dog and canary')

(d) *die Hunde und Kanarienvogel

the-M.PL dogs-M.PL and canary-M.SG

('the dogs and canary')

\subsection{INDEX systems: Russian}

Russian exemplifies the crosslinguistically most unusual system: one in which only INDEX requirements are imposed. We first examine the singular determiner ètot/èta/èto 'this', which patterns similarly to the singular determiner in the INDEX/CONCORD system of German and Brazilian Portuguese.

The singular determiner can be used with a nonconjoined singular noun, as in (6ra). Coordinated phrases with a singular determiner and singular conjoined nouns are disallowed if they refer to more than one individual, as 
in (6Ib); this is because the resulting phrase has a plural INDEX feature, which is incompatible with the requirements imposed by the singular determiner èta. In contrast, as shown in (62), syntactically similar examples that refer to a single individual, like moj drug $i$ kollega 'my friend and colleague', are acceptable, since such phrases have singular INDEX. ${ }^{\mathbf{1 7}}$

(6I) (a) èta ženščina

this-F.SG woman-F.SG

'this woman'

(b) *èta ženščina i devočka

this-F.SG woman-F.SG and girl-F.SG

('this woman and girl')

(62) moj/ètot drug i kollega

my-M.sG/this-M.SG friend-M.SG and colleague-M.SG

'my/this friend and colleague'

We now turn to the plural determiner èt $i$ it is here that the unique properties of the INDEX system emerge most clearly. Our account predicts that a determiner requiring plural INDEX is compatible with conjoined singular nouns, as long as the resulting phrase refers to more than one individual. The Russian plural demonstrative èt $i$ can appear with nonconjoined plural nouns, as shown in (63), and conjoined plurals, as in (64). It cannot be used with nonconjoined singular nouns, as in (65).

(63) èti mužčiny

these-PL man-M.PL

'these men'

(64) èti mužčiny i ženščiny

these-PL man-M.PL and woman-F.PL

'these men and women'

(65) *èti mužčina

these-PL man-M.SG

('these man')

Crucially, it is also possible to use plural èt $i$ with conjoined singular nouns : ${ }^{18}$

(66) èti mužčina i ženščina

these-PL man-M.SG and woman-F.SG

'this man and woman'

[I7] Thanks to Mike Polyakov and Alex Vasserman for the Russian data.

[18] Crockett (1976: chapter 3) discusses the pattern in (66), stating that this pattern is prescriptively approved, but in regular usage closest-conjunct agreement is found (p. I69). This is confirmed by Corbett (I983: I59-I62), who cites examples such as (i): 
We account for the grammaticality of examples like (66) by assuming that èt $i$ has a PL INDEX feature, as in (67).

$$
\begin{aligned}
\grave{e} t i & (\uparrow \text { SPEC })={ }^{\prime E} \mathrm{E} T I \\
& (\uparrow \text { INDEX NUM })=\mathrm{PL}
\end{aligned}
$$

The f-structure for example (66) is given in (68); it shows that èt $i$ constrains the INDEX value of the coordinate phrase as a whole, and so can be used even in cases where the conjuncts are singular.

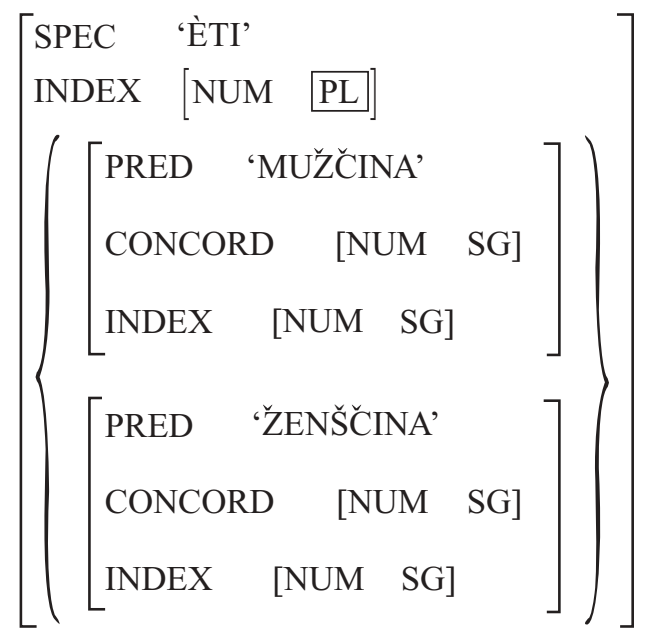

Unexpected additional constraints arise, however, in the case of mixed coordinate structures, where one of the conjuncts is singular and one plural. Our analysis predicts that èt should also be compatible with these examples; however, this does not appear to be the case. We have found only one or two naturally-occurring Russian examples of plural determiners with mixed coordinate constructions on the Internet (in sharp contrast to the very large number of examples of mixed coordination in a wide range of textual genres with the English determiners the and $m y$ ), and our informants indicate that such examples are not well-formed in general.

We currently have no explanation for this fact. Indeed, we have not found any determiner that is explicitly marked as a plural form that is compatible with mixed coordinated nouns; the only determiners we have found that are acceptable with mixed coordinated nouns are completely unmarked for

\footnotetext{
(i) ... so svoej ženoj, domom i fabrikoj with self's-F.SG wife-F.SG house-M.SG and factory-F.SG '.. with his own wife, house, and factory'
}

However, younger speakers, including the speakers we have consulted, prefer the plural determiner in examples like (66), providing evidence of a change in progress in determiner-noun agreement constraints in Russian. 
number, such as English the, Georgian es, and Armenian ais/aid (sections 2.2.3 and 3.2).

Interestingly, some English speakers also find mixed coordinated phrases like the man and boys unacceptable out of context. We speculate that the unacceptability of mixed coordinated nouns with a shared determiner might be due to either semantic or stylistic factors, or to a combination of the two. On some semantic proposals (e.g. Bennett I975; Winter I998), singular and plural nouns have different semantic types, and a special operation is necessary to adjust the type of either the singular or the plural conjunct so that they can be coordinated, perhaps with some associated cost. There may also be stylistic pressure towards uniform coordinate structures, in which case speakers would find mixed coordinate examples less acceptable out of context, but of improved acceptability in context. This may be the case for Russian as well as those English speakers who do not find English examples like the man and boys acceptable out of context.

\section{COMPARISON WITH PREVIOUS WORK}

There have been few previous proposals for treating the crosslinguistic variation found in determiner agreement with coordinated nouns. Schwartz et al. (I988) note that many analyses of coordination assume-either implicitly or explicitly - that if two singular words or phrases are coordinated, the singular value is only available below the scope of coordination, and above the scope of coordination only a plural value is available. In our terms, this amounts to examining only the INDEX feature, which is (in general) plural for a coordinated phrase, even when it is composed of singular conjuncts. And, indeed, the INDEX values of the individual conjuncts are not accessible above the scope of coordination; when the INDEX value of a coordinate set is constrained, no constraints are placed on the INDEX values of the conjuncts. However, our analysis of determiner agreement shows that even when the determiner modifies coordinated nouns and so is outside the scope of coordination, the CONCORD features of each conjunct (which are, in Schwartz et al.'s terms, below the scope of coordination) may be relevant for agreement.

In the semantic literature, there has been some discussion of the treatment of examples like the boy and girl or every boy and girl. Under a treatment of coordination as simple boolean conjunction, such phrases can refer only to individuals that are simultaneously boys and girls, and the more reasonable reading involving a group composed of boys and girls is not readily available (for discussion, see Bergmann I982; Partee \& Rooth I983; Dowty I988; Winter I998). We have seen that this reading is the only one available in German and Brazilian Portuguese for coordinated singular nouns sharing a singular determiner: in those languages, phrases like my friend and colleague are grammatical and refer to a single individual, while phrases like 
the boy and girl, which must refer to more than one individual, are ungrammatical. Our analysis attributes this distinction to a difference in agreement requirements: the singular determiners $o$ in Brazilian Portuguese and der in German require singular INDEX (and CONCORD) and can only be used to refer to a single individual, while the singular determiner this in English requires singular CONCORD but may be used to refer to more than one individual.

More recently, however, Heycock \& Zamparelli (1999, 2000) have proposed a semantic explanation for this difference. An account that successfully explained the contrasts we have examined in purely semantic terms would indeed be a valuable and interesting step forward, and so their account is worthy of examination as a possible alternative to the syntactic account that we present. In the following, we present a simplified version of their proposal, note some of its consequences, and show that it proves unsuccessful on several counts. In our discussion, we adopt Heycock \& Zamparelli's terminology, according to which a phrase like the boy and girl has a split interpretation, referring to more than one individual, while a phrase like my friend and colleague has a joint interpretation, referring to a single individual. Heycock \& Zamparelli's proposal is designed to provide an account of the fact that English allows both a split and joint interpretation for coordinated singular nouns sharing a singular determiner, while Italian is like Brazilian Portuguese and German in allowing only a joint interpretation for this construction.

Following Heycock \& Zamparelli's very clear exposition of their proposal, we proceed primarily by example. We assume a model consisting of the following individuals:

(69) boys: $b_{1}, b_{2}$

girls: $g_{1}, g_{2}$

Heycock \& Zamparelli (I999, 2000) assume the syntactic structure in (70) for a phrase like this boy and girl or my friend and colleague $(\mathrm{PlP}=$ plural phrase).

(70) [DP Det [ $\mathrm{NumP}_{\text {Num [PIP }}$ (Modifier) [NP Noun (Complement)]]]]

According to Heycock \& Zamparelli's theory, the noun phrases boy(s) and $\operatorname{girl}(s)$ have the following denotations:

(7I) denotation of boy/boys: $\left\{\left\{b_{1}\right\},\left\{b_{2}\right\}\right\}$ denotation of $\mathbf{g i r l} / \mathbf{g i r l s}:\left\{\left\{g_{1}\right\},\left\{g_{2}\right\}\right\}$

Number is represented by the feature \pm Plur, which is checked in PIP, and so at the NP level the denotation of singular and plural nouns is the same. Crucially, English and Italian differ as to what happens at each functional projection; this is described below.

The denotation of a coordinated NP in English and Italian is obtained by taking the 'set-product' (approximately, the crossproduct) of the sets 
represented by the conjuncts. In both languages, the denotation of [ $\mathrm{NP}_{\mathrm{NP}} \operatorname{boy}(s)$ and $\operatorname{girl}(s)]$ is as in (72).

(72) denotation of [NP boy(s) and girl(s)]:

$\left\{\left\{b_{1}, g_{1}\right\},\left\{b_{1}, g_{2}\right\},\left\{b_{2}, g_{1}\right\},\left\{b_{2}, g_{2}\right\}\right\}$

At P1P, the two languages differ. In both languages, the operation of 'generalized union' is relevant; this operation consists, approximately, in taking all possible subsets of the denotation of the NP, and unioning together each result (see Heycock \& Zamparelli I999, 2000 for more discussion). In English, the operation applies only in the presence of a + Plur feature, and not in the presence of a - Plur feature. In contrast, in Italian the operation is always performed. The denotation of PIP in each language is as follows:

English - Plur: the denotation of [PIP [NP boy and girl]] is unchanged:

$\left\{\left\{b_{1}, g_{1}\right\},\left\{b_{1}, g_{2}\right\},\left\{b_{2}, g_{1}\right\},\left\{b_{2}, g_{2}\right\}\right\}$

+ Plur: the denotation of [PIP [NP boys and girls]] is:

$\left\{\left\{b_{1}, g_{1}\right\},\left\{b_{1}, g_{2}\right\},\left\{b_{2}, g_{1}\right\},\left\{b_{2}, g_{2}\right\},\left\{b_{1}, g_{1}, g_{2}\right\},\left\{b_{2}, g_{1}, g_{2}\right\}\right.$,

$\left.\left\{b_{1}, b_{2}, g_{1}\right\},\left\{b_{1}, b_{2}, g_{2}\right\},\left\{b_{1}, b_{2}, g_{1}, g_{2}\right\}\right\}$

Italian \pm Plur [PIP [NP boy and girl]]/[PIP [NP boys and girls]]:

$$
\begin{aligned}
& \left\{\left\{b_{1}, g_{1}\right\},\left\{b_{1}, g_{2}\right\},\left\{b_{2}, g_{1}\right\},\left\{b_{2}, g_{2}\right\},\left\{b_{1}, g_{1}, g_{2}\right\},\left\{b_{2}, g_{1}, g_{2}\right\}\right. \text {, } \\
& \left.\left\{b_{1}, b_{2}, g_{1}\right\},\left\{b_{1}, b_{2}, g_{2}\right\},\left\{b_{1}, b_{2}, g_{1}, g_{2}\right\}\right\}
\end{aligned}
$$

The two languages also differ at NumP. If there is no overt numeral in English, no operation is performed. In Italian, the \pm Plur feature is again relevant, giving rise to a filter on the denotation of PIP. For - Plur phrases, only the singleton sets remain, while for + Plur phrases, only the sets with more than one member remain.

English: The denotation of boy and girl/boys and girls is the same as for PIP.

Italian: The denotation of - Plur [NumP [PIP [NP boy and girl]]] is empty, since there are no singletons in the denotation of Italian [PIP [NP boy and girl]].

The denotation of + Plur [NumP [PIP [NP boys and girls]]] is the same at NumP as it is at PIP, since there are no singletons in the set that must be filtered out.

Given the above model, the result for each language is as follows:

English [NumP [PIP [NP boy and girl]]]: $\left\{\left\{b_{1}, g_{1}\right\},\left\{b_{1}, g_{2}\right\},\left\{b_{2}, g_{1}\right\},\left\{b_{2}, g_{2}\right\}\right\}$

English [NumP [PIP [NP boys and girls]]]: $\left\{\left\{b_{1}, g_{1}\right\},\left\{b_{1}, g_{2}\right\},\left\{b_{2}, g_{1}\right\},\left\{b_{2}, g_{2}\right\},\left\{b_{1}, g_{1}, g_{2}\right\},\left\{b_{2}, g_{1}, g_{2}\right\}\right.$, $\left.\left\{b_{1}, b_{2}, g_{1}\right\},\left\{b_{1}, b_{2}, g_{2}\right\},\left\{b_{1}, b_{2}, g_{1}, g_{2}\right\}\right\}$

Italian [NumP [PIP [NP boy and girl]]]: \{\}

Italian [NumP [PIP [NP boys and girls]]:

$\left\{\left\{b_{1}, g_{1}\right\},\left\{b_{1}, g_{2}\right\},\left\{b_{2}, g_{1}\right\},\left\{b_{2}, g_{2}\right\},\left\{b_{1}, g_{1}, g_{2}\right\},\left\{b_{2}, g_{1}, g_{2}\right\}\right.$, $\left.\left\{b_{1}, b_{2}, g_{1}\right\},\left\{b_{1}, b_{2}, g_{2}\right\},\left\{b_{1}, b_{2}, g_{1}, g_{2}\right\}\right\}$ 
In sum, conditions at the various functional projections conspire to ensure that in Italian, the denotation of boy and girl is empty, while in English it is the pairs consisting of one boy and one girl. This means that a phrase like this boy and girl refers to a pair consisting of a boy and a girl in English (the split reading), but fails to refer in Italian, assuming there is no individual that is both a boy and a girl (no joint reading is available).

Still following Heycock \& Zamparelli's exposition, let us examine another model, one where the two sets overlap.

(73) friends: $f_{1}, f_{2}$

colleagues: $f_{1}, c_{1}$

denotation of friend: $\left\{\left\{f_{1}\right\},\left\{f_{2}\right\}\right\}$

denotation of colleague: $\left\{\left\{f_{1}\right\},\left\{c_{1}\right\}\right\}$

In this model, $f_{1}$ is both a friend and a colleague. For this new model, following their rules of semantic composition, the denotation in each language of friend(s) and colleague $(s)$ is as follows:

English [NumP [PIP [NP friend and colleague]]]:

$\left\{\left\{f_{1}\right\},\left\{f_{1}, c_{1}\right\},\left\{f_{1}, f_{2}\right\},\left\{f_{2}, c_{1}\right\}\right\}$

English [NumP [PIP [NP friends and colleagues]]]:

$\left\{\left\{f_{1}\right\},\left\{f_{1}, c_{1}\right\},\left\{f_{1}, f_{2}\right\},\left\{f_{2}, c_{1}\right\},\left\{f_{1}, f_{2}, c_{1}\right\}\right\}$

Italian [NumP [PIP [NP friend and colleague]]]: $\left\{\left\{f_{1}\right\}\right\}$

Italian [NumP [PIP [NP friends and colleagues]]]: $\left\{\left\{f_{1}, c_{1}\right\},\left\{f_{1}, f_{2}\right\},\left\{f_{2}, c_{1}\right\},\left\{f_{1}, f_{2}, c_{1}\right\}\right\}$

As Heycock \& Zamparelli note, the result of the differences they postulate between English and Italian is their prediction that an Italian phrase like l'amico e collaboratore di Gianni 'the friend and collaborator of Gianni' refers to any individual that is both a friend and collaborator (the joint reading), whereas an Italian phrase like questo soldato e marinaro 'this soldier and sailor' fails to refer (the split reading), since if there is no individual that is both a soldier and a sailor, the phrase 'soldier and sailor' fails to denote anything.

There are several problems with this account. First, consider the denotation that Heycock \& Zamparelli propose for the English plural phrase friends and colleagues, given the model in (73) above.

(74) friends and colleagues: $\left\{\left\{f_{1}\right\},\left\{f_{1}, c_{1}\right\},\left\{f_{1}, f_{2}\right\},\left\{f_{2}, c_{1}\right\},\left\{f_{1}, f_{2}, c_{1}\right\}\right\}$

This phrase is felicitously used to refer to a group of individuals, each of whom is both a friend and a colleague. The presence of the singleton $\left\{f_{1}\right\}$ in this set incorrectly entails that a phrase like my friends and colleagues can refer to some single individual $f_{1}$, who is my friend and colleague. This is a direct consequence of Heycock \& Zamparelli's proposal to include singleton sets in the denotation of plural phrases in English. 
Second, examples of mixed singular/plural coordination, discussed in sections 2.2.3 and 3.2 above, provide a formal challenge for this account. Heycock \& Zamparelli claim that in the analysis of a phrase like the cat and $\operatorname{dog}$, the feature - Plur raises across-the-board from the coordinated $\mathrm{N}$ structure and is checked by a higher projection. With mixed singular/plural coordinate examples like the cat and $\operatorname{dog} s$, however, the Plur features on the noun conjuncts are different, and no across-the-board raising can occur. It is unclear exactly what Heycock \& Zamparelli's analysis predicts for this case, since the authors do not discuss examples of feature raising with mixed singular/plural coordinated nouns. It is clear that the correct interpretation cannot be obtained if a -Plur feature is raised, since the phrase the cat and dogs does not refer to pairs consisting of one cat and one dog, but instead to groups consisting of one cat and several dogs. However, if a + Plur feature is somehow passed up from a mixed coordinate noun structure, not only is the wrong interpretation still obtained (the interpretation would be the same as for the cats and dogs, referring to groups which may contain several cats and several dogs), but examples like *these cat and $\operatorname{dog} s$ are also incorrectly predicted to be grammatical.

More seriously, Heycock \& Zamparelli"s attempt to account for the difference between split and joint readings makes the wrong typological predictions. Their account predicts a two-way typological distinction between English-like languages, which allow split and joint readings in both singular and plural, and Italian-like languages, which allow split and joint readings only in the plural and not in the singular. ${ }^{19}$ The account does not extend to languages like Greek, which allow only a joint reading for both singular and plural noun coordination. ${ }^{20}$ Example (75), which involves conjoined plural nouns and admits only a split reading, is unacceptable in Greek. ${ }^{21}$

(75) *oi gátes kai kóttes

the-PL cat-F.PL and chicken-F.PL

'the cats and chickens'

[19] Heycock \& Zamparelli (2000: section 7) discuss restrictions involving postnominal complementation and modification that account for the ungrammaticality of some cases of plural coordinated nouns with shared plural determiners. Apparently, these restrictions apply both for split and joint readings, and so any account of these examples would be syntactically based and would not affect the overall approach to the distinction between split and joint readings that Heycock \& Zamparelli propose.

[20] Thanks to Stella Markantonatou and Cleo Condoravdi for the Greek data.

[2I] The acceptability of examples like (i) seems to counterexemplify this claim:

(i) merikés gátes kai kóttes

several-F.PL cat-F.PL and chicken-F.PL

'several cats and chickens'

As pointed out by Cleo Condoravdi (p.c.), however, such examples lack a partitive reading, which would be associated with an analysis of merikés 'several' as a determiner; the only reading available is a cardinal/existential reading, under which merikés would be analyzed adjectivally. Therefore, such examples do not, in fact, present a problem. 
In contrast, example (76) is acceptable, but only on a joint reading (on which each individual is both a friend and a colleague).

(76) oi

oi fíloi kai sinádelfoi mou
the-PL friend-M.PL and colleague-M.PL my
'my friends and colleagues'

Heycock \& Zamparelli's approach does not allow for an account of this contrast. In English and Italian, the joint reading is only available by virtue of the interactions of the set-forming and filtering operations on the denotations of conjoined nouns. No such analysis is available here: there is no way to pick out a set of individuals who are both friends and colleagues by the operations that Heycock \& Zamparelli describe. The Greek data suggest instead that the distinction between split and joint readings is orthogonal to the group-forming semantic operations that operate in the interpretation of coordinate structures and that the split/joint distinction cannot be treated merely as a side effect of such operations.

\section{CONCLUSION}

We have presented a puzzle in the analysis of examples like This boy and girl (are eating a pizza): such phrases require singular determiners, but plural verb agreement. The solution to this puzzle leads to a general typology of agreement features within the noun phrase. CONCORD features are distributive features, associated only with the conjuncts in a coordinate phrase; INDEX features, in contrast, are nondistributive features associated with the coordinate phrase as a whole. Our theory predicts a particular set of possible agreement patterns for determiners with coordinated nouns, all of which are attested. In future work, we hope to extend our account to encompass prenominal adjective agreement, which will require a close examination of the interaction of the gender and number features in noun coordination, and also to integrate a treatment of closest-conjunct agreement into our account.

\section{REFERENCES}

Bennett, M. (1975). Some extensions of a Montague fragment of English. Ph.D. dissertation, University of California, Los Angeles.

Bergmann, M. (1982). Cross-categorial semantics for conjoined common nouns. Linguistics and Philosophy 5. 399-40I.

Bloomfield, L. (I933). Language. London: George Allen \& Unwin. [Reprinted I96I, Holt, Reinhart \& Winston.]

Bresnan, J. (200I). Lexical-functional syntax. Oxford: Blackwell Publishers.

Butt, M. \& King, T. H. (eds.). On-line Proceedings of the LFG20oo Conference. http://cslipublications.stanford.edu/LFG/.

Corbett, G. G. (1983). Hierarchies, targets, and controllers: agreement patterns in Slavic. London: Croom Helm.

Corbett, G. G. (200I). Agreement: terms and boundaries. In The role of agreement in natural language: Proceedings of the 200I Texas Linguistic Society Conference. I09-I22. 


\section{DETERMINER AGREEMENT AND NOUN CONJUNCTION}

Crockett, D. B. (1976). Agreement in contemporary standard Russian. Cambridge, MA: Slavica Publishers Inc.

Dalrymple, M. (200I). Lexical functional grammar (Syntax and Semantics 34). New York: Academic Press.

Dalrymple, M. \& Kaplan, R. M. (2000). Feature indeterminacy and feature resolution. Language 76. 759-798.

Dalrymple, M., Kaplan, R. M., Maxwell, J. T., III \& Zaenen, A. (eds.) (I995). Formal issues in Lexical-Functional Grammar. Stanford, CA: CSLI Publications.

Dowty, D. R. (I988). Type-raising, functional composition, and non-constituent conjunction. In Oehrle, R. T., Bach, E. \& Wheeler, D. (eds.), Categorial grammars and natural language semantics. Dordrecht: D. Reidel. I53-I97.

Falk, Y. N. (200I). Lexical-Functional Grammar: an introduction to parallel constraint-based syntax. Stanford, CA: CSLI Publications.

Greenberg, J. H. (I978). How does a language acquire gender markers? In Greenberg, J. H., Ferguson, C. A. \& Moravcsik, E. A. (eds.), Universals of human language: word structure (vol. 3). Stanford, CA: Stanford University Press. 47-82.

Grimes, B. F. (1999). Ethnologue: languages of the world. SIL International. www.sil.org/ ethnologue/.

Heycock, C. \& Zamparelli, R. (I999). Toward a unified analysis of DP conjunction. In Dekker, P. (ed.), Proceedings of the Twelfth Amsterdam Colloquium. ILLC, University of Amsterdam. I27-I32.

Heycock, C. \& Zamparelli, R. (2000). Friends and colleagues: plurality and NP-coordination. In Hirotani, M., Coetzee, A., Hall, N. \& Kim, J.-Y. (eds.), Proceedings of the 3oth Annual Meeting of the North Eastern Linguistic Society 30. Rutgers University.

Kaplan, R. M. \& Maxwell, J. T., III (I988). Constituent coordination in LexicalFunctional Grammar. In Proceedings of the I2th International Conference on Computational Linguistics (COLING88), Budapest (vol. I). 303-305. [Reprinted in Dalrymple et al. (eds.), I99-2I0.]

Kathol, A. (I999). Agreement and the syntax-morphology interface in HPSG. In Levine, R. \& Green, G. (eds.), Studies in current phrase structure grammar. Cambridge: Cambridge University Press. 223-274.

Moravcsik, E. A. (I978). Agreement. In Greenberg, J. H., Ferguson, C. A. \& Moravcsik, E. A. (eds.), Universals of human language: syntax (vol. 4). Stanford, CA: Stanford University Press. 33I-374.

Munn, A. (2000). Three types of coordination asymmetries. In Schwabe, K. \& Zhang, N. (eds.), Ellipsis in conjunction. Tübingen: Max Niemeyer Verlag. I-22.

Partee, B. \& Rooth, M. (I983). Generalized conjunction and type ambiguity. In Bauerle, R., Schwarze, C. \& von Stechow, A. (eds.), Meaning, use, and interpretation of language. Berlin: W. de Gruyter. 36I-383.

Plank, F. (I99I). Ellipsis and inflection of determiners and modifiers in coordinate NPs (Technical Report II). EUROTYP Working Papers, European Science Foundation.

Pollard, C. \& Sag, I. A. (I994). Head-driven phrase structure grammar. Chicago: The University of Chicago Press.

Sadler, L. (I999). Non-distributive features and coordination in Welsh. In Butt, M. \& King, T. H (eds.), http://csli-publications.stanford.edu/LFG/4/lfg99.html.

Sadler, L. (2003). Asymmetric coordination and agreement in LFG. In Butt, M. \& King, T. H. (eds.), Nominals: inside and out. Stanford, CA: CSLI Publications. 85-II7.

Schwartz, L., Newman, P. \& Sani, S. (I988). Agreement and scope of modification in Hausa coordinate structures. In Brentari, D., Larson, G. \& MacLeod, L. (eds.), Papers from the 24th Regional Meeting of the Chicago Linguistic Society, part 2: Parasession on Agreement in Grammatical Theory. University of Chicago: Chicago Linguistic Society. $278-290$.

Vincent, N. \& Börjars, K. (2000). Feature resolution and the content of features. In Butt, M. \& King, T. H. (eds.), http://csli-publications.stanford.edu/LFG/5/lfgoo.html.

Wechsler, S. (2002). Elsewhere in gender resolution. In Hanson, K. \& Inkelas, S. (eds.), The nature of the word: essays in honor of Paul Kiparsky. Cambridge, MA: MIT Press.

Wechsler, S. \& Zlatić, L. (2000). A theory of agreement and its application to Serbo-Croatian. Language 76. 759-798. 


\section{T. H. KING \& M. DALR Y MPLE}

Wechsler, S. \& Zlatić, L. (2003). The many faces of agreement: morphology, syntax, semantics, and discourse factors in Serbo-Croatian agreement. Stanford, CA: CSLI Publications.

Winter, Y. (1998). Flexible boolean semantics. Ph.D. dissertation, Utrecht University.

Authors' addresses: (King)

Palo Alto Research Center, 3333 Coyote Hill Road, Palo Alto,

CA 94304, U.S.A.

E-mail:thking@parc.com

(Dalrymple)

Department of Computer Science, King's College London,

London $W C 2 R 2 L S, U . K$.

E-mail:mary@dcs.kcl.ac.uk 